\title{
Nonlinear Analysis of a Collapsed Reinforced Concrete Chimney
}

\author{
Phillip L. GOULD $*$, Wei HUANG ${ }^{\mathrm{a}}$, \\ Washington University, Saint Louis, MO, 63130,pgoul@seas.wustl.edu \\ ${ }^{a}$ KPFF Consulting Engineers, Los Angeles, CA, 90045, whuang@kpff-la.com
}

\begin{abstract}
During the Ismit (Kocaeli) Earthquake of August 17, 1999, a $115 \mathrm{~m}$. High reinforced concrete chimney or heater stack, located at the Tüpras Refinery, collapsed. The falling debris cut 63 pipes, which contributed to interrupted production for more than 14 months. This stack was designed and constructed according to international standards and is representative of similar structures at refineries throughout the world, including those in earthquake-prone regions. It was distinguished from similar stacks at the site by a much larger rectangular opening for a flue duct, circumscribing a horizontal arc of about $50^{\circ}$. The opening was located about $1 / 3$ of the height above the base and appeared to be the region of initiation of the collapse. The investigation is focused on the dynamic response of the stack due to anearthquake motion recorded at a nearby site. In this study, the results of a response spectrum analysis of the Tüpras stack and a generic U.S. stack are summarized. Then, a two dimensional nonlinear static pushover analysis of the collapsed Tüpras stack is presented using a demand-collapse comparison. Different pushover methods for the consideration of the higher mode effects, including traditional pushover procedures as well as the newly developed Modal Pushover Analysis (MPA) procedure, are evaluated. In order to consider three dimensional interaction effects, a new 3-D pushover analysis procedure is proposed and applied to the Tüpras stack. Finally, a full nonlinear dynamic analysis of the Tüpras stack is introduced to verify the pushover analysis and show more clearly the failure mechanism of the stack during the earthquake. Results are presented that show the effects of the opening and the orientation of the motion with respect to the opening. Higher mode contributions and three dimensional interaction effects are considered. The results confirm that the stack could readily fail under the considered earthquake and are also consistent with the debris pattern.
\end{abstract}

Keywords: Concrete Chimney, Collapse, Dynamic Response, Pushover Analysis. 


\section{Introduction}

During the Izmit (Kocaeli) Earthquake of August 17, 1999, a $115 \mathrm{~m}$. high reinforced concrete chimney or heater stack, located at the Tüpras Refinery, collapsed. This stack was designed and constructed according to international standards and is representative of similar structures at refineries throughout the world, including those in earthquake-prone regions. This structure is of particular interest because several similar chimneys at the site survived the shock with only moderate damage.

The overall objectives of the study are four fold:

1. To evaluate the original design of the collapsed chimney, known as the Tüpras stack, using current analysis techniques.

2. To evaluate the design of a similar size chimney representative of U. S. practice.

3. To explain why the single stack in question did indeed collapse while several similar structures in the same vicinity survived with minimal damage through the use of advanced seismic evaluation tools.

4. To extend the pushover analysis procedure for chimney structures by taking into account the higher modes and the three dimensional interaction effects.

The first three objectives were addressed earlier [1, 2, and 3] by a response spectrum analysis based on the unsmoothed YPT record as well as the UBC 97 design spectrum.

The input for the study is a single strong motion record recorded at a site near the failed stack, named the YPT (A Petro-Chemical Plant in Körfez, Turkey) record. No other nearby record is available, so this record is adopted as the input motion for the analysis of the Tüpras stack. For the YPT longitudinal spectrum (YPTx) and transverse spectrum (YPTy), along with a modern design code spectrum, UBC 97 (1997 Uniform Building Code) spectrum, several demand curves are plotted in the spectral acceleration vs. spectral displacement domain (ADRS) as shown in Figures 1 and 2. The ADRS spectrum is converted from the ordinary response spectrum using the relationship between acceleration, displacement and period from simple harmonic motion in order to permit comparisons with the capacity curve. Note that any radial line from the origin represents a constant period on all of the intersected demand curves. Also included on the figures are the first mode pushover capacity curves for different loading conditions, among which a profile oriented 90 degrees to the opening is the critical pushover case. The construction of these curves is explained in later paragraphs.

The damping ratios for intact reinforced concrete chimney structures are fairly low, typically in the range of $2 \%$ to $5 \%$. Following the usual practice for reinforced concrete, five percent damping was used. 


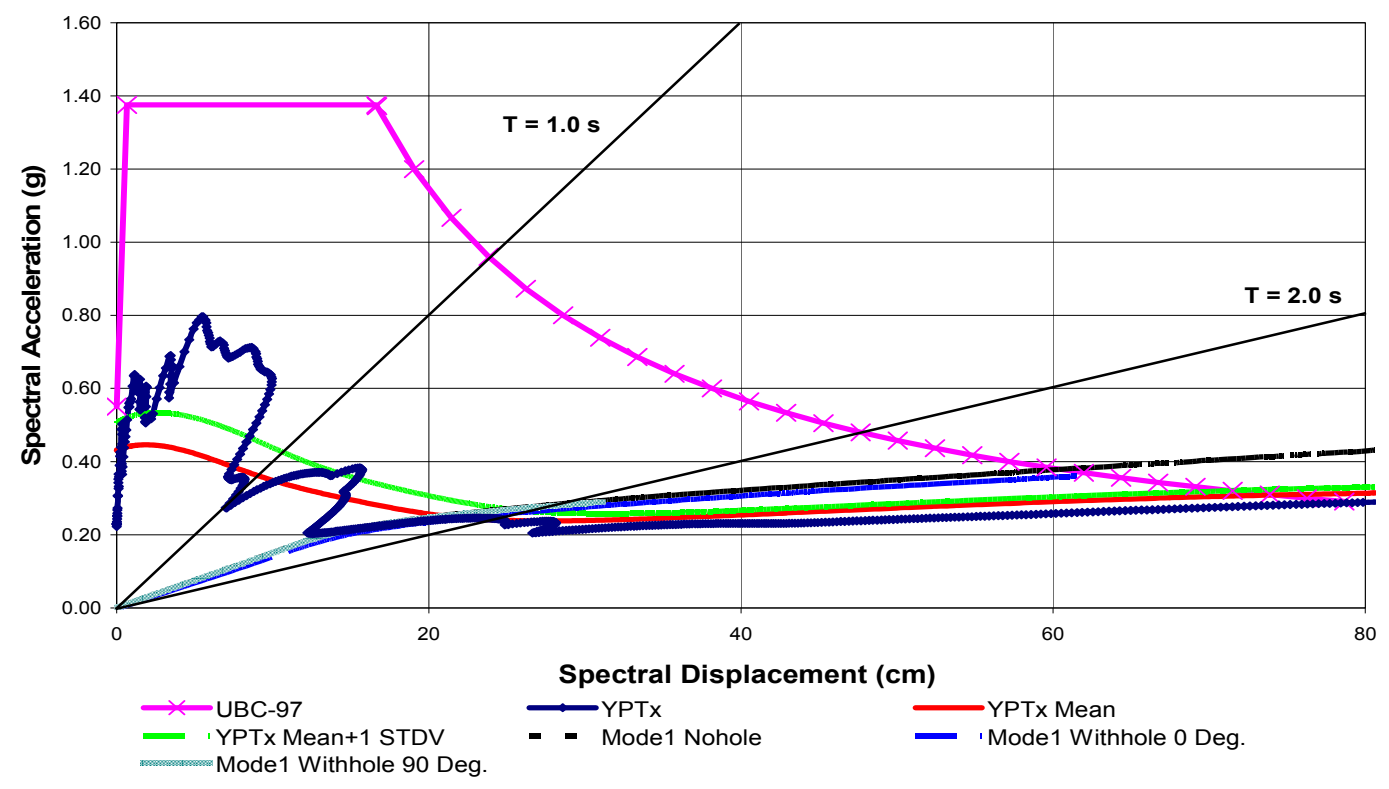

FIGURE 1 - MODE 1 CAPACITY CURVES VS. YPTX DEMAND CURVES 


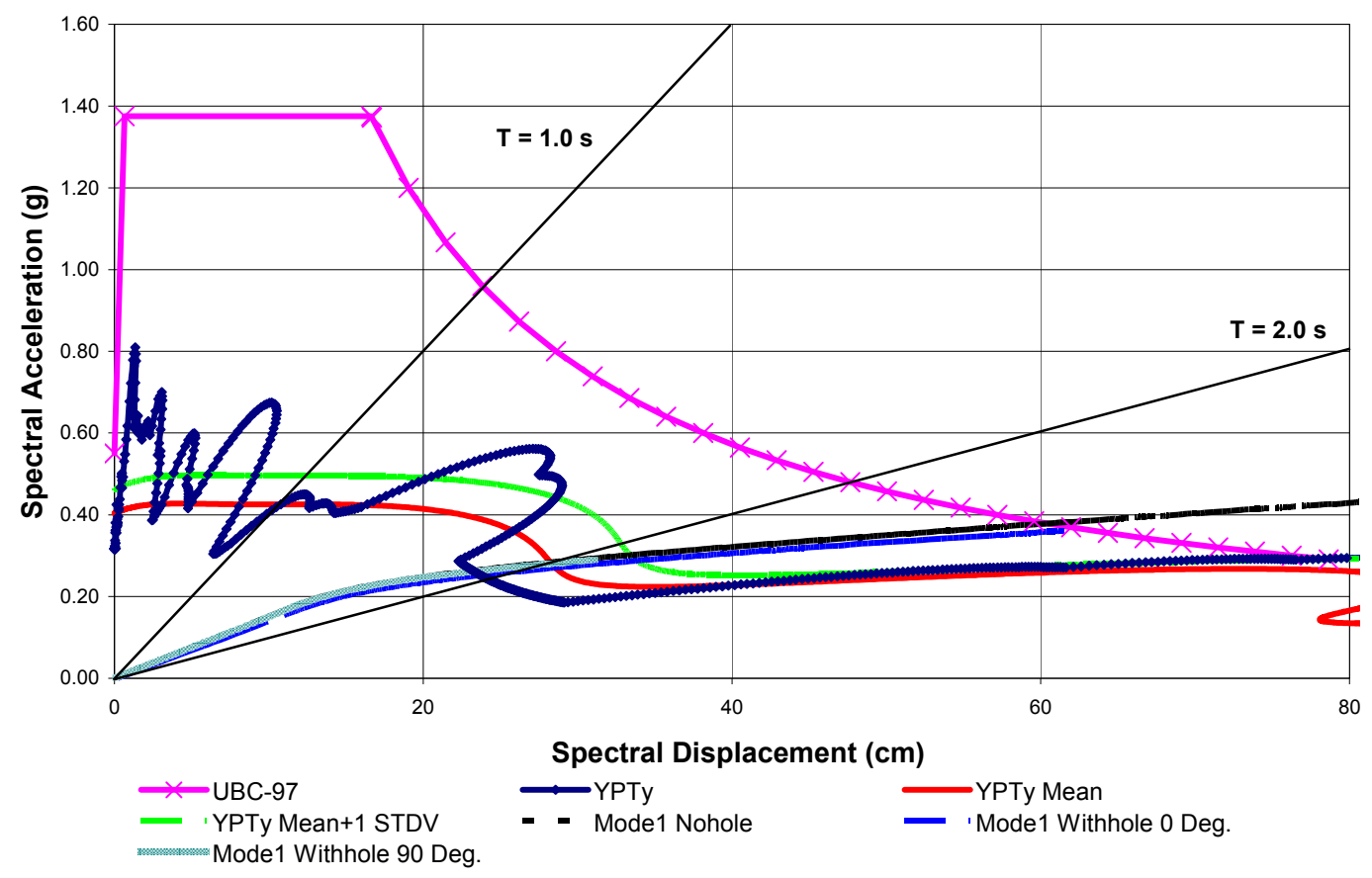

FIGURE 2 - MODE 1 CAPACITY CURVES VS. YPTY DEMAND CURVES

\section{3-D Pushover Analysis}

\section{A New 3-D Pushover Analysis Procedure}

In traditional pushover analysis, only the distribution of forces equivalent to that produced by earthquake action in one direction is applied to the structure to represent the inertia forces experienced during the earthquake. This procedure has provided insightful results for symmetric structures. But for asymmetric structures, pushover analysis considering two directional earthquake input may be more appropriate, since the structure has different dynamic properties in each direction. For the Tüpras stack, with the large opening at the 30 meter level, the stack would have undergone different lateral motions simultaneously and the 3-D interaction effects may not be negligible. There is very little research focusing on improving the pushover analysis by considering three dimensional interaction effects $[4,5]$, so the need for developing improved pushover analysis procedures considering 3-D interaction effects for asymmetric structures is evident. 
In this study, a new 3-D pushover analysis method is proposed to extend the traditional 2-D pushover procedure for the analysis of the asymmetric Tüpras stack. The validity of the proposed method will be assessed by comparing the results with those from an "exact" 3-D step-by-step nonlinear dynamic analysis. The basic procedure is as follows:

1. Carry out a three dimensional modal analysis using a finite element model with the initial geometry and material properties. Obtain the natural frequencies and fundamental modes for each direction.

2. Now, two types of lateral load patterns may be selected based on the basic patterns. One type is a fundamental mode, usually Mode 1, and the other type may be one of the basic patterns other than Mode 1 .

3. For a lateral load pattern other than the fundamental mode patterns, apply the lateral forces to the structure, and perform the pushover analysis for each direction. Plot the pushover curves in the spectral displacement vs. spectral acceleration domain (ADRS). The equivalent SDF period for the lateral load pattern in each direction is then taken as the initial secant for the pushover curve before yielding.

4. For each direction, given the fundamental frequencies for the fundamental modes and equivalent SDF system frequencies for the other load patterns, locate the corresponding spectral acceleration values from the response spectrum in each direction (In this case, the longitudinal and transverse directions of the YPT spectrum).

5. Apply two directional lateral forces for each load pattern to the structure proportional to the spectral acceleration values obtained from Step 3.

6. For each load pattern, perform the 3-D pushover analysis using the lateral load forces described in Step 4, and plot the capacity curve for each direction.

7. Compare the capacity curves with the smoothed mean demand curves of the spectra for each direction to obtain the target displacement of the structure for different load patterns.

8. Determine the response over the height of the structure using the 3-D pushover analysis results for the different patterns at the respective target displacements.

\section{3-D Pushover Analysis Results}

First, the 3-D pushover procedure is applied to the model without an opening and compared to 3-D nonlinear dynamic analysis with two directional inputs. Then the procedure is extended to predict the failure of the model with the opening. The failure analysis for the model with the opening is carried out by $3-\mathrm{D}$ nonlinear dynamic analysis as well.

\section{Model without an opening}




\begin{tabular}{lllll}
\hline \multirow{2}{*}{ Method } & \multicolumn{2}{l}{ 3-D Pushover } & \multicolumn{2}{l}{ 2-D Pushover } \\
\cline { 2 - 5 } & Disp. $(\mathrm{m})$ & Error (\%) & Disp. (m) & Error (\%) \\
\hline Mode 1 & 0.522 & -13.1 & 0.498 & -17.1 \\
Uniform & 0.416 & -30.8 & 0.316 & -47.4 \\
ELF & 0.680 & 13.1 & 0.492 & -18.1 \\
Triangle & 0.701 & 16.6 & 0.476 & -20.8 \\
SRSS & 0.662 & 10.1 & 0.629 & 4.7 \\
MPA & 0.565 & -6.0 & 0.528 & -12.2 \\
NL RHA & 0.601 & 0 & - & - \\
\hline
\end{tabular}

\section{TABLE 1 - TARGET DISPLACEMENTS FOR THE MODEL WITHOUT AN OPENING}

Similar to the traditional 2-D pushover analysis, target displacements are calculated by the proposed 3-D pushover analysis, based on different lateral load patterns as well as the MPA procedure. These target displacements using 3-D and 2-D pushover analysis, given in Table 1 , are the magnitudes of the displacement of the stack at the top. As shown in the table, 3-D pushover analysis results are based on the YPT earthquake input in both directions while 2$\mathrm{D}$ results are based on YPTy earthquake input in one direction. They are calculated by combining the results of target displacements for each direction. The errors are obtained by comparison to the nonlinear response history analysis results (NL RHA).

As seen in Table 1, for 3-D pushover analysis results, the error from the Uniform distribution is the largest, while the Mode 1 distribution, ELF distribution, and Triangle distribution errors are less. Taking into account the higher mode effects, the SRSS distribution gives a good prediction for the target displacement, and the error from the MPA procedure [6] is less than $10 \%$. In general, the new 3-D pushover analysis provides better estimations for the target displacement when compared to 2-D pushover analysis since the pushover load patterns are simulating the earthquake inputs in both directions.

\section{Model with the opening}

Since the stack failed in an earthquake having different lateral loading components acting simultaneously, it is appropriate to analyze the structure in multiple directions. The failure displacement and the cracking pattern recorded at the failure point from 3-D nonlinear dynamic analysis will be used to validate the 3-D pushover procedure.

The 3-D pushover procedure was applied to the model with the opening, where the lateral load patterns in the two directions are proportional to the response spectrum values based on the equivalent SDF system. Also, a 3-D nonlinear dynamic analysis was carried out using two directional inputs, a suite of YPT longitudinal records in the direction 0 degrees to the opening, and a suite of YPT transverse records in the direction 90 degrees to the opening, based on the orientation of the opening from the site reference.

The failure displacement at the top and the cracking patterns are compared between the 3-D pushover analysis prediction and the 3-D nonlinear dynamic analysis results. Because 
the pushover analysis results for the three fundamental modes can not be combined for failure analysis since the failure displacement is determined for each mode by pushing the structure to its capacity in that mode, the MPA procedure is not considered here.

Failure displacement

Incremental lateral loads in two directions for different loading patterns were applied on the structure until failure. The magnitudes of the top displacement at the point of failure, as predicted by the different pushover patterns, are shown in Table 2 . The errors relative to the 3-D nonlinear response history analysis (NL RHA) are listed as well.

\begin{tabular}{lll}
\hline \multirow{2}{*}{ Pattern } & \multicolumn{2}{l}{ YPT Mean } \\
\cline { 2 - 3 } & Failure Disp. (m) & Error (\%) \\
\hline Mode 1 & 0.667 & 27.0 \\
Uniform & 0.745 & 41.8 \\
ELF & 0.646 & 23.1 \\
Triangle & 0.645 & 22.8 \\
SRSS & 0.597 & 13.8 \\
NL RHA & 0.525 & 0 \\
\hline
\end{tabular}

\section{TABLE 2 - 3-D FAILURE DISPLACEMENTS FOR THE MODEL WITH THE OPENING}

As shown in Table 2, where results taking into account higher mode effects in both directions are summarized, the SRSS distribution provides the best prediction, with less than $14 \%$ error.

Cracking pattern

Cracking patterns for the 3-D pushover analysis has been studied and the results will not be shown in this paper. In the failure cracking pattern from nonlinear dynamic analysis, there are more long critical shear cracks around the opening area than there are flexural cracks along the height. This finding confirms the initial prediction by 2-D pushover analysis; the critical shear cracks developed at the opening area caused the stack to fail during that earthquake. The cracking patterns from 3-D pushover analysis show the existence of the critical shear cracks around the top left and bottom right corner of the opening. Considering the limitation of monotonic loading, we would expect a symmetric cracking pattern for the other direction, so the overall cracking patterns around the opening under cyclic loading match well with the nonlinear dynamic analysis results. Even though all lateral patterns give good estimations at the opening level, the SRSS distribution, by taking into account the higher mode contribution, better predicts the cracks developed from the opening level to about the $65 \mathrm{~m}$ level. 


\section{Conclusions}

Using a demand-capacity comparison, a nonlinear static pushover analysis was used to investigate the collapsed Tüpras stack. The demand was represented by an accelerationdisplacement response spectrum based on the YPT record motion as well as some smoothed adaptations typical of design spectra. The capacities were calculated from pushover curves using a nonlinear reinforced concrete finite element analysis. A new 3-D pushover analysis procedure was proposed and the results were compared with those from a nonlinear dynamic analysis. Results are presented that show the importance of the 3-D interaction effects in the dynamic response of stacks.

\section{Acknowledgement}

The authors wish to thank the United States National Science Foundation for the support of this study under grant CMS-0084737.

\section{References}

[1] [1]Gould, Phillip L., Huang, Wei, Martinez, Raul, and Johnson, Gayle S., "Investigation of the Collapse of a Heater Stack during the Izmit (Kocaeli) Turkey Earthquake of August 17, 1999", Proc. 7th U.S. Nat. Conf. on Earthquake Engineering, Boston, MA, July 2002. Also presented in Proc. 12th European Conference on Earthquake Engineering, London, U. K., September 2002.

[2] [2] Gould, Phillip L., Huang, Wei, and Johnson, Gayle S., "Nonlinear analysis of a collapsed stack", Proc. 13th World Conference on Earthquake Engineering, Vancouver, British Columbia, Canada, August 2004.

[3] [3]Huang, Wei, Gould, Phillip L., Martinez, Raul, and Johnson, Gayle S., "Nonlinear analysis of a collapsed reinforced concrete chimney", Earthquake Engineering \& Structural Dynamics, 2004, 33:485-498.

[4] [4]Ayala, A. G. and Travera, E. A., "A new approach for the evaluation of the seismic performance of asymmetric buildings", Proc. 7th U.S. Nat. Conf. on Earthquake Engineering, Boston, MA, July, 2002, (CD-ROM).

[5] [5] Moghadam, A. S. and Tso, W. K., "Pushover Analysis for Asymmetrical Multistory Buildings", Proc. 6th U.S. National conf. Earthquake Engineering, Seattle, EERI, Oakland, 1998.

[6] [6] Chopra, A. K. and Goel, R. K., "A modal pushover analysis procedure for estimating seismic demands for buildings", Earthquake Engineering \& Structural Dynamics, Vol. 31, 2002, pp. 561-582. 